\title{
Effects of docosanyl ferulate, a constituent of Withania somnifera, on ethanol- and morphine-elicited conditioned place preference and ERK phosphorylation in the accumbens shell of CD1 mice
}

\author{
Riccardo Maccioni ${ }^{1} \cdot$ Marcello Serra $^{2}$ - Jacopo Marongiu ${ }^{2} \cdot$ Filippo Cottiglia $^{1}$ - Elias Maccioni ${ }^{1} \cdot$ Valentina Bassareo $^{2,3}$. \\ Micaela Morelli ${ }^{2,3} \cdot$ Sanjay B. Kasture ${ }^{4} \cdot$ Elio Acquas $^{1,3}[$
}

Received: 6 September 2021 / Accepted: 17 January 2022 / Published online: 28 January 2022

(c) The Author(s) 2022

\begin{abstract}
Background Docosanyl ferulate (DF) is a behaviourally active $\mathrm{GABA}_{\mathrm{A}}$ receptor complex $\left(\mathrm{GABA}_{\mathrm{A}} \mathrm{R}\right)$ agonist, recently isolated from the standardized methanolic extract of Withania somnifera Dunal (WSE) root. Previous studies have shown that WSE prevents both ethanol- and morphine-dependent acquisition and expression of conditioned place preference (CPP) and stimulation of dopamine release in the nucleus accumbens shell (AcbSh).

Aims The study aimed at determining (a) whether DF contributes to WSE's ability to affect the acquisition and expression of ethanol- and morphine-elicited CPP and, given that phosphorylation of extracellular signal-regulated kinase (pERK) in the AcbSh is involved in associative learning and motivated behaviours, (b) whether WSE and DF may affect ethanol- and morphine-induced ERKs phosphorylation in the AcbSh.

Methods In adult male CD1 mice, DF's effects on the acquisition and expression of ethanol- and morphine-elicited CPP were evaluated by a classical place conditioning paradigm, whereas the effects of WSE and DF on ethanol- and morphineelicited pERK in the AcbSh were evaluated by immunohistochemistry.

Results and conclusions The study shows that DF, differently from WSE, affects only the acquisition but not the expression of ethanol- and morphine-induced CPP. Moreover, the study shows that both WSE and DF can prevent ethanol- and morphine-elicited pERK expression in the AcbSh. Overall, these results highlight subtle but critical differences for the role of $\mathrm{GABA}_{\mathrm{A}} \mathrm{Rs}$ in the mechanism by which WSE affects these ethanol- and morphine-dependent behavioural and molecular/ cellular responses and support the suggestion of WSE and DF for the control of different components of drug addiction.
\end{abstract}

Keywords Conditioned place preference $\cdot$ Docosanyl ferulate $\cdot$ Ethanol $\cdot$ ERK $\cdot$ Morphine $\cdot$ pERK $\cdot$ Withania somnifera

\section{Introduction}

Drug addiction is defined as the progressive loss of control over drug taking caused by repeated exposures to addictive drugs. This is the consequence of a series of

Elio Acquas

acquas@unica.it

1 Department of Life and Environmental Sciences, University of Cagliari, Cagliari, Italy

2 Department of Biomedical Sciences, University of Cagliari, Cagliari, Italy

3 Center of Excellence for the Study of Neurobiology of Addiction, University of Cagliari, Cagliari, Italy

4 Pinnacle Biomedical Research Institute, Bhopal, India neuroadaptations, occurring in selective neural circuits, which leads to the development of a chronic neuroadaptive disorder characterized by behavioural alterations in which compulsive drug-seeking and high risk of relapse play a critical role (Berke and Hyman 2000; Koob 2006; Koob and Le Moal 2001; Nestler 2001; Volkow and Morales 2015). Ethanol and morphine are two substances that are well-characterized to induce such neuroadaptations. Accordingly, ethanol is one of the most used and abused psychoactive substances worldwide, is a high-risk factor for several multi organ diseases (Axley et al. 2019; Rehm et al. 2017) and is responsible for the potential of alcoholic drinks to trigger their pathological consumption (Abrahao et al. 2017). Morphine is, instead, the lead compound prescribed for the treatment of multiple and diverse chronic painful conditions and although developing addiction is not an issue in this case, a high rate 
of dependence in those who take morphine chronically has been reported with debilitating side-effects such as constipation and respiratory depression (Benyamin et al. 2008). Notably, although the mechanism of action by which ethanol and morphine may elicit addiction is different, though not fully understood, these drugs share the ability to increase mesolimbic dopamine (DA) transmission (Di Chiara et al. 2004; Bassareo et al. 2019, 2021) and induce the phosphorylation and subsequent activation of the extracellular signal-regulated kinases (ERKs) (Ibba et al. 2009; Porru et al. 2020; Rosas et al. 2016; Spina et al. 2015; Valjent et al. 2004), two biochemical indexes critical for addiction-related behaviour in laboratory studies (Di Chiara 1999; Di Chiara et al. 2004).

The conditioned place preference (CPP) paradigm, widely used to study the rewarding properties of unconditioned stimuli (drugs, food, sex, etc.), is endowed with great translational impact due to its face, construct and predictive validity (Tzschentke 2007). The acquisition and the expression of CPP are two critical phases of this paradigm. In particular, the acquisition of place conditioning is grounded on associative learning (Di Chiara et al. 2004) and represents the phase in which the reinforcing properties of an unconditioned stimulus are transferred to the conditioned, otherwise neutral, stimulus; on the other hand, the expression of place conditioning represents the phase in which the reinforcing properties of the unconditioned stimulus that have been transferred to the conditioned one are recognized (recalling) by the animals that may hence emit a response toward that stimulus (positive side-preference shift: animals spend, in the environment associated with the unconditioned stimulus, longer time than before conditioning). Thus, in translational perspective, acquisition and expression of CPP, by modelling two distinct critical conditions of the clinical, naturalistic, setting of drug addiction allow to investigate, respectively, the phase in which subjects attribute drug's reinforcing properties to the context (acquisition and/or maintenance of drug-taking) and that in which the conditioned stimulus becomes eventually capable of triggering relapse into drug-taking (expression, reinstatement). This, in turn, makes treatments that may prevent any of these critical phases of drug addiction highly desirable.

ERKs are part of the mitogen-activated protein kinase (MAPK) signalling cascade and play a central role in signal transduction, neuroplasticity and gene expression (Sweatt 2004) as well as in the behavioural changes underlying the reinforcing processes induced by drugs of abuse (Valjent et al. 2005). ERKs are highly expressed also in rewardrelated brain areas and their activation through phosphorylation (pERK) occurs after both acute (Acquas et al. 2007; Brami-Cherrier et al. 2006; Ibba et al. 2009; Rosas et al. 2016) or chronic (Berhow et al. 1996; Muller and Unterwald 2004) administration of drugs of abuse. Notably, both acquisition and expression of place conditioning have been strictly associated with the increased activation, by phosphorylation, of ERKs. In particular, ERKs phosphorylation has been shown to be increased, in key brain regions such as those of the mesolimbic system and the extended amygdala, during the acquisition and expression of place conditioning (Gerdjikov et al. 2004; Mazzucchelli et al. 2002; Porru et al. 2020; Salzmann et al. 2003; Valjent et al. 2000, 2001). Accordingly, several studies have demonstrated that the pharmacological inhibition of the mitogen activating ERK kinase (MEK), the kinase responsible for ERKs phosphorylation (Sweatt 2004), prevents pERK expression and CPP acquisition elicited by several drugs of abuse (Gerdjikov et al. 2004; Lu et al. 2006; Porru et al. 2020; Salzmann et al. 2003; Spina et al. 2010; Valjent et al. 2000, 2001), including ethanol (Rosas et al. 2017), its metabolite, acetaldehyde (Correa et al. 2012; Spina et al. 2010) and morphine (Lin et al. 2010; Spina et al. 2010). On a similar vein, place conditioning and self-administration studies have shown that increased pERK is strictly associated with the emission of the acquired response (CPP expression) (Mazzucchelli et al. 2002; Porru et al. 2020) and, consequently, prevention of ERKs phosphorylation during the post-conditioning test prevents the behavioural outcome (CPP expression) (Rosas et al. 2017; Porru et al. 2020). Thus, increased ERKs phosphorylation appears involved, although with some exceptions (Rosas et al. 2018), not only in the attribution of motivational value to neutral stimuli when paired with the primary effects of addictive substances (acquisition of conditioned responses) (Gerdjikov et al. 2004; Rosas et al. 2018; Valjent et al. 2001) but also in the recognition and recall of drug-conditioned stimuli (expression, i.e. behavioural response to presentation of conditioned stimuli) (Mazzucchelli et al. 2002; Porru et al. 2020).

Withania somnifera (WS) Dunal is a medicinal plant originally included in the Ayurveda, the Indian traditional system of medicine, whose central properties extend from anxiolytic and neuroprotective to anti-inflammatory and anti-neurodegenerative (Dar et al. 2015; Maccioni et al. 2018; Singh et al. 2011). Interestingly, WS's standardized methanolic root extract (WSE) has also been reported, in preclinical rodent models of drug addiction, to prevent the acquisition and the expression of ethanol (Spina et al. 2015)and morphine (Ruiu et al. 2013)-elicited CPP. Moreover, recent evidence demonstrated that WSE, through a $\mathrm{GABA}_{\mathrm{A}}$ receptor complex $\left(\mathrm{GABA}_{\mathrm{A}} \mathrm{R}\right)$-mediated mechanism, also prevents the ethanol- and morphine-dependent increases of DA transmission in the rat nucleus accumbens shell (AcbSh) (Bassareo et al. 2019). This evidence, given the role of mesolimbic DA in drug-elicited place conditioning (Acquas and Di Chiara 1994; Di Chiara et al. 2004; Fenu et al. 2006), suggests a plausible mechanism for WSE's positive effects on motivated behaviours. 
Based on these premises, given (i) the profile of docosanyl ferulate (DF) as most active constituent of WSE on $\mathrm{GABA}_{\mathrm{A}} \mathrm{R}$ (Sonar et al. 2019) with anxiolytic properties without sedative, amnesic, motivational and motor coordination-impairing effects (Maccioni et al. 2021), and (ii) the importance of the proposed $\mathrm{GABA}_{\mathrm{A}} \mathrm{R}$-mediated mechanism for WSE's actions on mesolimbic DA function (Bassareo et al. 2019), the present study aimed at verifying, whether $\mathrm{DF}$ could affect the acquisition and/or the expression of ethanol- and morphine-induced CPP. Moreover, based on the critical connection between CPP and ERKs activation (Gerdjikov et al. 2004; Lu et al. 2006; Mazzucchelli et al. 2002; Porru et al. 2020; Salzmann et al. 2003; Spina et al. 2010; Valjent et al. 2000; Valjent et al. 2001), the study also aimed at verifying whether $W S E$, at a dose $(50 \mathrm{mg} / \mathrm{kg})$ at which it prevents acquisition and expression of ethanol (Spina et al. 2015)- and morphine (Ruiu et al. 2013)-elicited CPP, and $\mathrm{DF}$, at a dose $(2 \mathrm{mg} / \mathrm{kg})$, at which it shows robust anxiolytic properties with no undesired side-effects (Maccioni et al. 2021), could prevent pERK expression elicited by ethanol (Porru et al. 2020; Rosas et al. 2017) or morphine (Rosas et al. 2016) in the AcbSh.

\section{Materials and methods}

\section{Animals}

Adult male CD1 mice (22-24 g, Charles River, Calco, Italy) $(n=305)$ were housed in groups of eight per cage for at least 6 days before the experiments began, under a 12:00/12:00 $\mathrm{h}$ light/dark cycle (lights on at 08:00 a.m.) with food (Mucedola Srl, Settimo Milanese, Milan, Italy) and water available ad libitum. All the experiments were carried out during the light phase, between 09:00 and 18:00 h. The total number of mice used for CPP and immunohistochemistry experiments was 179 and 126, respectively. All the experimental procedures were performed in accordance with the principles of laboratory animal care, with the guidelines and protocols approved by the European Union (2010/63/UE L 276 20/10/2010) and with the approval of the local committee (authorization number 371/2020-PR). Every possible effort was made to minimize animal pain and discomfort and to reduce the number of experimental subjects.

\section{Drugs}

Ethanol (EtOH) (Sigma-Aldrich, Milan, Italy) was diluted in saline $(\mathrm{NaCl} 0.9 \% \mathrm{w} / \mathrm{v})$ to $20 \%(\mathrm{v} / \mathrm{v})$ and administered at the dose of $2 \mathrm{~g} / \mathrm{kg}$ (12.5 ml/kg volume injection). Morphine hydrochloride (MOR) (Franchini Prodotti Chimici Srl, Mozzate, Como, Italy) was dissolved in saline $(10 \mathrm{ml} / \mathrm{kg}$ volume injection) and administered at the dose of $5 \mathrm{mg} / \mathrm{kg}$.
The standardized methanolic extract of the root of Withania somnifera, WSE (Natural Remedies Pvt Ltd, Bangalore, India) was dissolved in saline and administered at the dose of $50 \mathrm{mg} / \mathrm{kg}$ (10 ml/kg volume injection). Docosanyl ferulate (DF), synthesized (purity $>98 \%$ by HPLC) according to Sonar et al. (2019), dissolved in Tween 80 (Sigma-Aldrich, Milan, Italy) and suspended in saline, was administered at the dose of $2 \mathrm{mg} / \mathrm{kg}$ ( $10 \mathrm{ml} / \mathrm{kg}$ volume injection). Sodium pentobarbital (Pentothal Sodium, MSD Animal Health S.r.l, Italy) was dissolved in saline and administered at the dose of $50 \mathrm{mg} / \mathrm{kg}$. All drugs were administered intraperitoneally (i.p.) at doses in accordance with previous experiments (Ibba et al. 2009; Maccioni et al. 2021; Porru et al. 2020; Rosas et al. 2016; Ruiu et al. 2013; Spina et al. 2015).

\section{Conditioned place preference (CPP)}

The apparatus consisted of two rectangular Plexiglas boxes $(48 \mathrm{~L} \times 20 \mathrm{~W} \times 30 \mathrm{H} \mathrm{cm})$ separated by a guillotine door, placed in a sound-proof room with a constant light of 37.5 Lux (ELD 9010 Luxmeter, Eldes Instruments, Italy) provided by a $40 \mathrm{~W}$ lamp placed above each compartment. Different visual and tactile cues distinguished the two compartments: vertically striped black and white walls and white smooth floor for one compartment (A), and horizontally striped black and grey walls and fine grid floor for the other compartment (B). The spontaneous preference was randomly distributed between compartments (49\% for compartment A and $51 \%$ for compartment B) and did not differ statistically amongst the experimental groups (Table 1).

\section{CPP acquisition experiments}

The experiment consisted of three phases. During the first phase (pre-conditioning test, day 1), the guillotine door was kept raised and each mouse was placed randomly in one compartment and given access to both compartments of the apparatus for $15 \mathrm{~min}$ (900 s). The time spent in one compartment was recorded and taken as indication of spontaneous preference. During the second phase (conditioning, days 2-5), mice of the experimental groups (as indicated above) were administered (pre-treatment) either vehicle (Veh) or $\mathrm{DF}$ and returned to their home cages for $30 \mathrm{~min}$. At the end of this period, mice were administered (treatment) either vehicle (Veh) or ethanol (EtOH) or morphine (MOR) and exposed for $30 \mathrm{~min}$ to the given compartment. On the same day, $8 \mathrm{~h}$ later, mice of all groups were administered Veh or $\mathrm{DF}$ (pre-treatment) and, after $30 \mathrm{~min}$, immediately after being administered the drug (EtOH or MOR) or Veh (treatment), were exposed to the opposite compartment for $30 \mathrm{~min}$. The sequence of the administrations of Veh or DF, as pre-treatment, and of Veh or drug (EtOH or MOR), as treatment, was alternated in the following days so that on consecutive days 
Table 1 Average preconditioning test time $(\mathrm{sec} / 900 \pm \mathrm{SEM})$ (spontaneous preference) of the experimental groups of the acquisition and expression experiments

\begin{tabular}{|c|c|c|c|}
\hline Experimental group & $\begin{array}{l}\text { Spontaneous preference } \\
\text { (seconds/900 } \pm \text { SEM) }\end{array}$ & $N$ & One-way ANOVA \\
\hline Acquisition of ethanol-induced CPP & & & {$\left[F_{(3,52)}=0.61, p>0.05\right]$} \\
\hline Veh/Veh & $379 \pm 15$ & 12 & \\
\hline DF/Veh & $348 \pm 28$ & 10 & \\
\hline $\mathrm{Veh} / \mathrm{EtOH}$ & $379 \pm 24$ & 16 & \\
\hline $\mathrm{DF} / \mathrm{EtOH}$ & $389 \pm 16$ & 18 & \\
\hline Acquisition of morphine-induced CPP & & & {$\left[F_{(3,40)}=0.08, p>0.05\right]$} \\
\hline Veh/Veh & $394 \pm 16$ & 12 & \\
\hline DF/Veh & $386 \pm 20$ & 10 & \\
\hline Veh/MOR & $382 \pm 20$ & 12 & \\
\hline DF/MOR & $385 \pm 18$ & 10 & \\
\hline Expression of ethanol-induced CPP & & & {$\left[F_{(3,35)}=0.16, p>0.05\right]$} \\
\hline Veh/Veh + Veh & $394 \pm 20$ & 10 & \\
\hline Veh/Veh + DF & $390 \pm 18$ & 8 & \\
\hline $\mathrm{Veh} / \mathrm{EtOH}+\mathrm{Veh}$ & $376 \pm 27$ & 8 & \\
\hline $\mathrm{Veh} / \mathrm{EtOH}+\mathrm{DF}$ & $387 \pm 10$ & 13 & \\
\hline Expression of morphine-induced CPP & & & {$\left[F_{(3,36)}=0.03, p>0.05\right]$} \\
\hline Veh/Veh + Veh & $394 \pm 20$ & 10 & \\
\hline Veh/Veh + DF & $391 \pm 18$ & 8 & \\
\hline Veh/MOR + Veh & $392 \pm 16$ & 9 & \\
\hline Veh/MOR + DF & $387 \pm 17$ & 13 & \\
\hline
\end{tabular}

mice never received Veh or DF (pre-treatment) and Veh or $\mathrm{EtOH}$ or MOR (treatment) administrations in the same order. During the third phase (post-conditioning test, day 6), $24 \mathrm{~h}$ after the last conditioning session, the guillotine door was kept raised and the time spent, out of $15 \mathrm{~min}$, by each mouse in the drug-paired compartment was recorded. The conditions of the post-conditioning test were identical to those of the pre-conditioning test. Performances at the pre- and postconditioning tests were videotaped and subsequently analysed in blind. A statistically significant difference between the time spent during pre- and post-conditioning tests (side preference shift) of the drug group with respect to that of the vehicle group was taken as indication of the development of place conditioning.

\section{CPP expression experiments}

The general protocol was the same of the one used for the acquisition experiments with two differences: (i) during conditioning (phase 2), mice were administered only Veh (pre-treatment) and either Veh or EtOH or MOR (treatment) (groups: Veh/Veh and Veh/EtOh or Veh/MOR) and (ii) $30 \mathrm{~min}$ before performing the post-conditioning test (phase 3 ), mice were administered either Veh or DF (groups: Veh/ $\mathrm{Veh}+\mathrm{Veh}, \mathrm{Veh} / \mathrm{Veh}+\mathrm{DF}, \mathrm{Veh} / \mathrm{EtOh}$ or Veh/MOR + Veh and Veh/EtOh or Veh/MOR + DF). As for the post-conditioning test of the acquisition experiments, a statistically significant difference between the time spent during pre- and post-conditioning tests (side preference shift) of the drug group with respect to that of the vehicle group was taken as indication of the expression of place conditioning.

\section{Immunohistochemistry}

Drug-elicited ERKs phosphorylation in the AcbSh is critical for the acquisition of drug-elicited place conditioning (Gerdjikov et al. 2004; Salzmann et al. 2003). The immunohistochemistry experiments of this study have been planned in order to investigate whether WSE and DF may prevent the ability of ethanol and morphine to elicit ERKs phosphorylation in the AcbSh. This was done in order to allow us to indirectly infer that WSE's (Spina et al. 2015; Ruiu et al. 2013) and DF's (present study) property to prevent CPP acquisition may be attributed to their ability to affect ethanol- or morphine-elicited ERKs phosphorylation. Thus, since for this technique, animals have to be sacrificed in order to allow processing their brains, distinct cohorts of animals were utilized for these experiments. Mice of different experimental groups were carried out in the experimental room and given $1 \mathrm{~h}$ of habituation time. Subsequently, they were administered Veh or WSE $(50 \mathrm{mg} / \mathrm{kg})$ or DF $(2 \mathrm{mg} / \mathrm{kg})$ (pre-treatment). After $30 \mathrm{~min}$, mice were administered Veh or EtOH $(2 \mathrm{~g} / \mathrm{kg})$ or MOR $(5 \mathrm{mg} / \mathrm{kg})$ (treatment). Experimental groups consisted, accordingly, in Veh/Veh $(n=8)$, WSE/Veh $(n=8), \mathrm{Veh} / \mathrm{EtOH}(n=6)$ and WSE/EtOH $(n=6)$ and Veh/Veh $(n=8), W S E / V e h(n=8)$, Veh/MOR $(n=8)$, 
$W S E / M O R(n=10)$ for the experiments performed with vehicle and WSE as pre-treatment; Veh/Veh $(n=8), \mathrm{DF} /$ Veh $(n=7), \mathrm{Veh} / \mathrm{EtOH}(n=7), \mathrm{DF} / \mathrm{EtOH}(n=9)$ and Veh/ Veh $(n=8)$, DF/Veh $(n=7)$, Veh/MOR $(n=8), \mathrm{DF} / \mathrm{MOR}$ $(n=10)$ for the experiments performed with vehicle or DF as pre-treatment. Mice of the ethanol-related experiments were anesthetized, with sodium pentobarbital $(50 \mathrm{mg} / \mathrm{kg}$ ), 15 min after the treatment (Ibba et al. 2009; Rosas et al. 2017), whilst subjects of the morphine-related experiments were anesthetized, with sodium pentobarbital $(50 \mathrm{mg} / \mathrm{kg})$, $20 \mathrm{~min}$ after the treatment (Rosas et al. 2016). Under deep anaesthesia, animals were subjected to transcardial perfusion with $0.9 \% \mathrm{NaCl}$ followed by ice-cold $4 \%$ paraformaldehyde (PFA) in $0.1 \mathrm{M}$ phosphate buffer solution (PBS) (137 mM $\mathrm{NaCl}, 2.7 \mathrm{mM} \mathrm{KCl}, 10 \mathrm{mM} \mathrm{Na} \mathrm{HPO}_{4}, 2 \mathrm{mM} \mathrm{KH}_{2} \mathrm{PO}_{4}, \mathrm{pH}$ 7.4). After perfusion, brains were removed and post-fixed for $2 \mathrm{~h}$ in $4 \%$ PFA $\left(4{ }^{\circ} \mathrm{C}\right)$. Two coronal brain slices $(40 \mu \mathrm{m})$ of the region of interest were cut on ice-cold PBS with a vibratome (Leica VT1000, Leica, Germany) according to plates 21-23 (approximately from antero-posterior (AP) 1.18 to AP $0.98 \mathrm{~mm}$ from bregma) of the Paxinos and Franklin (2001) mouse brain atlas. Sections were then processed under the diaminobenzidine (DAB) technique to quantify neurons positive to the phospho (44/42)-extracellular signal-regulated kinases (pERK) as a marker of neuronal activation. After three rinses in PBS, sections were first incubated for $30 \mathrm{~min}$ in $1 \% \mathrm{H}_{2} \mathrm{O}_{2}$, and then for $1 \mathrm{~h}$ in $3 \%$ bovine serum albumin (BSA) (Sigma-Aldrich, Milan, Italy). The incubation with the primary anti pERK antibody (Cell Signalling Technology, Beverly, MA, USA (1:350)) was conducted overnight at $4{ }^{\circ} \mathrm{C}$. The following day, after rinsing in PBS, slices were incubated for $1 \mathrm{~h}$ with the biotinylated secondary antibody (1:800). After three rinses, slices were incubated in an avidin biotin peroxidase complex prepared according to the manufacturer's suggestions (Vectastain ABC kit, Vector Laboratories, Burlingame, CA, USA) and a 3-3'-diaminobenzidine solution $(10 \mathrm{mg} / \mathrm{ml})$ was added until development of brown staining. Finally, sections were mounted onto glass slides coated with gelatine in Eukitt mounting medium for microscope visualization. Standard control experiments were performed by omission of the primary or secondary antibody and yielded no cellular labelling (data not shown). Images were obtained with an epifluorescence microscope (Axio Scope A1, Zeiss, Germany) connected to a digital camera (1.4 MPixels, Infinity 3-1, Lumenera, Canada). Brain sections immune-stained for pERK were evaluated using a 10X objective lens to acquire two images representing the whole left and right AcbSh. Then, the total number of pERK positive neurons was counted by using the manual particle counting option of ImageJ software (U.S. National Institutes of Health, Bethesda, MD, USA). Analysis was performed in a blinded manner. Since no significant differences in the counts of pERK-positive neurons were found amongst the two coronal sections of the AcbSh from the same mouse, values obtained from these sections were averaged.

\section{Statistical analysis}

To determine statistically significant differences between pre-conditioning values of the experimental groups, oneway analysis of variance (ANOVA) was applied. To determine the effects of pre-treatment (vehicle or DF) and treatment (vehicle or ethanol or morphine) as well as of their interaction on acquisition of CPP, data were analysed by three-way ANOVAs with pre-treatment and treatment as independent factors (between subjects), and with pre-conditioning and post-conditioning values as a within-subjects factor (repeated measures). To determine the statistically significant effects of DF on CPP expression, three-way ANOVAs, with preference times (pre- and post-conditioning) as dependent factors, and with conditioning treatment (Veh or EtOH or MOR) and post-conditioning test treatment (Veh or DF) as independent factors, as well as their interactions, were conducted. All statistical analyses were carried out (StatSoft, v. 8.0, StatSoft Inc., Tulsa (OK), USA) using data from the experimental groups depicted in each figure. Newman-Keuls post-hoc analyses also between preand post-conditioning times within each conditioning group were undertaken if significant effects were found $(p<0.05)$.

pERK-positive neurons/area following each treatment were expressed as the average number of pERK-positive neurons/area of each experimental group and indicated as pERK-positive neurons/area (pERK expression). These values were used for statistical analyses by two-way ANOVAs with pERK-positive neurons/area as dependent variables and with pre-treatment (vehicle or WSE or DF) and treatment (vehicle or ethanol or morphine) as independent variables. All statistical analyses were carried out using data from the experimental groups depicted in each figure. Newman-Keuls post-hoc analyses were undertaken if significant effects were found $(p<0.05)$.

\section{Results}

\section{Effects of DF on acquisition and expression of ethanol-induced CPP}

Figure 1A shows the effects of pre-treatment with vehicle (Veh) or DF (2 mg/kg) $30 \mathrm{~min}$ before the administration of vehicle (Veh) or ethanol (EtOH) and exposure to the associated compartment for $30 \mathrm{~min}$. One-way ANOVA revealed that pre-conditioning preference times did not significantly differ between experimental groups $(p>0.05)$. Repeated measures three-way ANOVA with preference times (pre- and post-conditioning) as dependent factors, 
Fig. 1 Effects of DF $(2 \mathrm{mg} / \mathrm{kg}$ i.p.) on ethanol-induced $\mathrm{CPP}$ acquisition (A) and expression (B). Histograms represent the time (seconds/900) spent in the drug-paired compartment before and after conditioning expressed as mean + SEM. *indicates a significant difference $(p<0.05)$ vs pre-conditioning, same experimental group, in Fig. 1A; ${ }^{\circ}$ indicates a significant difference $(p<0.05)$ vs pre-conditioning, same experimental groups, in Fig. 1B
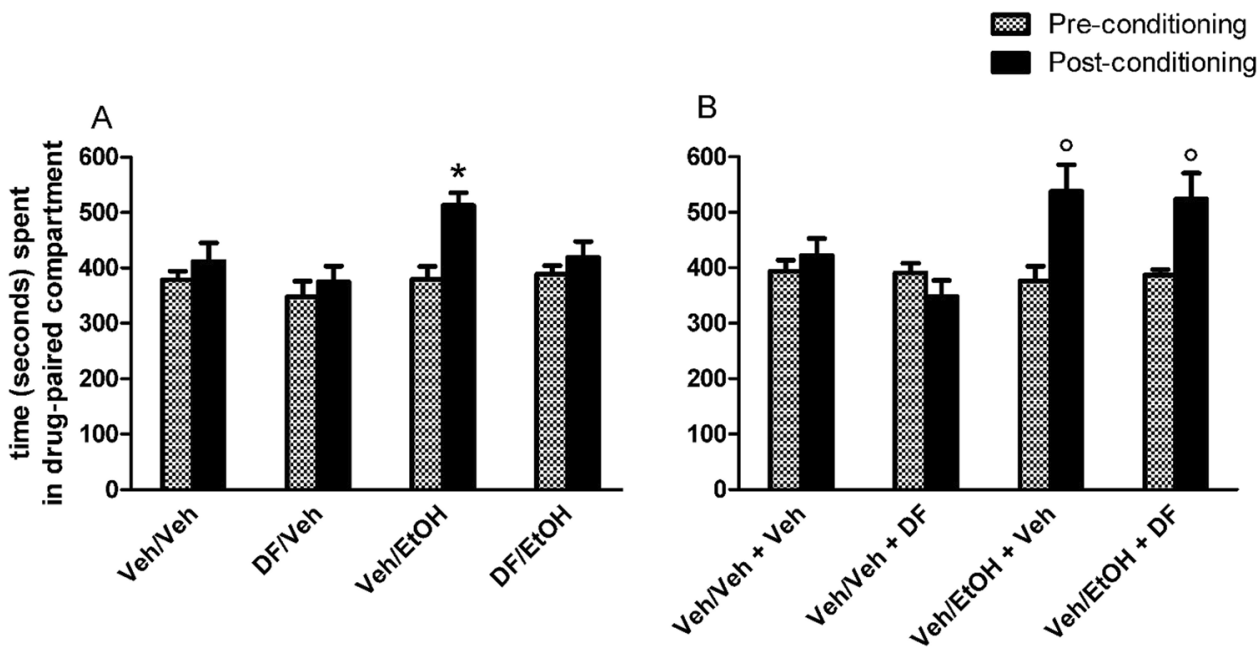

and with pre-treatment (Veh or DF) and treatment (Veh or $\mathrm{EtOH})$ as independent factors, revealed significant effects of time $\left[F_{(1,52)}=9.40, p<0.005\right]$, pre-treatment $\left[F_{(1,52)}=4.39\right.$, $p<0.05]$ and treatment $\left[F_{(1,52)}=6.58, p<0.05\right]$ confirming that $\mathrm{EtOH}$ stimulates a significant preference shift (Porru et al. 2020; Spina et al. 2015), indicating that DF on its own is devoid of conditioning properties (Maccioni et al. 2021) and suggesting that it may significantly prevent the acquisition of CPP induced by EtOH $(p<0.05)$. Figure 1B shows the effects of treatment with vehicle (Veh) or DF $(2 \mathrm{mg} / \mathrm{kg}$ ) $30 \mathrm{~min}$ before the exposure to the two compartments for the post-conditioning test of mice conditioned with (pretreatment/treatment) Veh/Veh and Veh/EtOH. One-way ANOVA revealed that pre-conditioning preference times did not significantly differ between experimental groups $(p>0.05)$. Repeated measures three-way ANOVA with preference times (pre- and post-conditioning) as dependent factors, and with conditioning treatment (Veh or $\mathrm{EtOH}$ ) and post-conditioning test treatment (Veh or DF) as independent factors, revealed significant effects of time $\left[F_{(1,35)}=9.59\right.$, $p<0.005]$ and conditioning-treatment $\left[F_{(1,35)}=7.96\right.$, $p<0.05]$, and a significant time by conditioning-treatment interaction $\left[F_{(1,35)}=11.69, p<0.005\right]$ but not a significant effect of post-conditioning test treatment $\left[F_{(1,35)}=0.71\right.$, $p>0.05$ ] confirming that EtOH stimulates a significant preference shift $(p<0.05)$ and that DF fails to prevent this effect; in fact, EtOH-conditioned and DF-treated (30 min before the post-conditioning test) mice had a significant shift from $387 \pm 10$ to $524 \pm 47 \mathrm{~s} / 900(p<0.05)$, underlying that DF fails to affect the expression of EtOH-induced CPP.

\section{Effects of DF on acquisition and expression of morphine-induced CPP}

Figure 2A shows the effects of pre-treatment with vehicle (Veh) or DF (2 mg/kg), 30 min before the administration
Fig. 2 Effects of DF $(2 \mathrm{mg} / \mathrm{kg}$ i.p.) on morphine-induced CPP acquisition (A) and expression (B). Histograms represent the time (seconds/900) spent in the drug-paired compartment before and after conditioning expressed as mean + SEM. *indicates a significant difference $(p<0.05)$ vs all groups in Fig. 2A; ${ }^{\circ}$ indicates a significant difference $(p<0.05)$ vs the Veh/Veh + Veh and $\mathrm{Veh} / \mathrm{Veh}+\mathrm{DF}$ groups in Fig. 2B
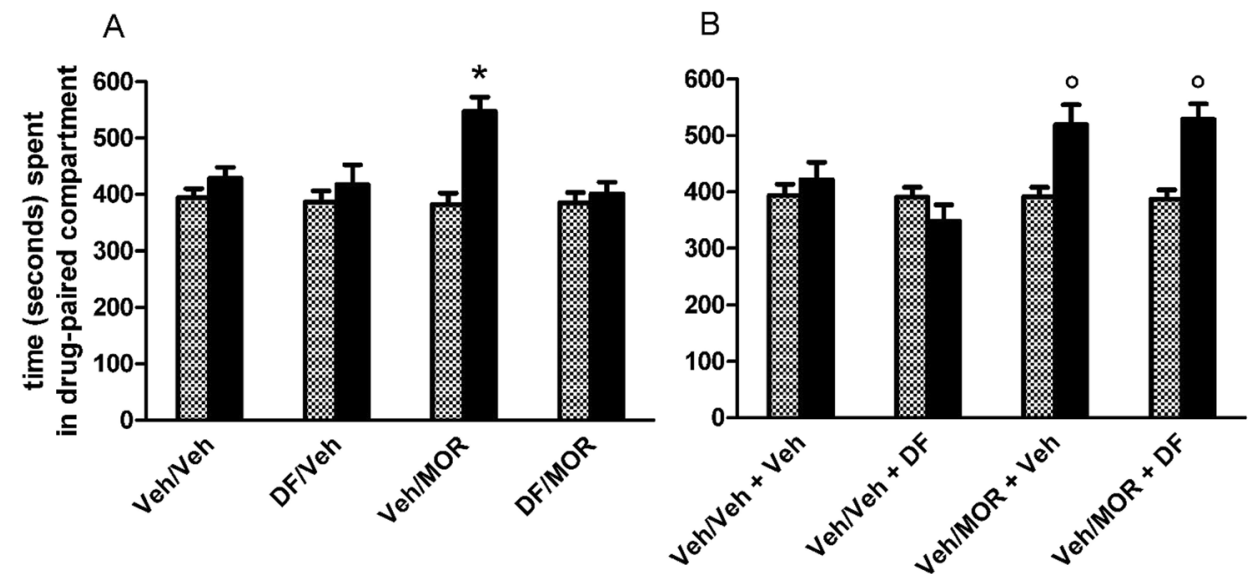
of vehicle (Veh) or morphine (MOR) and exposure to the associated compartment for $30 \mathrm{~min}$. One-way ANOVA revealed that pre-conditioning preference times did not significantly differ between experimental groups $(p>0.05)$. Repeated measures three-way ANOVA with preference times (pre- and post-conditioning) as dependent factors, and with pre-treatment (Veh or DF) and treatment (Veh or MOR) as independent factors, revealed significant effects of time $\left[F_{(1,40)}=14.02, p<0.005\right]$ and pre-treatment $\left[F_{(1,40)}=7.05, p<0.05\right]$ and significant time by pre-treatment $\left[F_{(1,40)}=5.34, p<0.05\right]$ and time by pre-treatment by treatment $\left[F_{(1,40)}=4.85, p<0.05\right]$ interactions. Posthoc analysis using the Newman-Keuls test confirmed that morphine stimulates a significant preference shift from $382 \pm 20$ to $547 \pm 26 \mathrm{~s} / 900(p<0.05)$ (Ruiu et al. 2013) and that DF is devoid of conditioning properties (Maccioni et al. 2021) and showed that DF significantly prevents the acquisition of CPP induced by morphine $(p<0.05)$. Figure $2 \mathrm{~B}$ shows the effects of treatment with vehicle (Veh) or DF 30 min before exposure to the two compartments for the post-conditioning test of mice conditioned with Veh/ Veh and Veh/MOR (pre-treatment/treatment). One-way ANOVA revealed that pre-conditioning preference times did not significantly differ between experimental groups $(p>0.05)$. Repeated measures three-way ANOVA with preference times (pre- and post-conditioning) as dependent factors, and with conditioning (Veh or MOR) and postconditioning test treatments (Veh or DF) as independent factors, revealed significant effects of time $\left[F_{(1,36)}=11.24\right.$, $p<0.005]$ and conditioning-treatment $\left[F_{(1,36)}=15.73\right.$, $p<0.005]$ and a significant time by conditioning-treatment interaction $\left[F_{(1,36)}=14.01, p<0.001\right]$ but not a significant effect of post-conditioning test treatment $\left[F_{(1,36)}=1.10\right.$, $p>0.05$ ] confirming that morphine stimulates a significant preference shift from $392 \pm 16$ to $519 \pm 35 \mathrm{~s} / 900(p<0.05)$ and that the post-conditioning test treatment with DF fails to prevent this effect; in fact, morphine-conditioned and DF-treated (30 min before the post-conditioning test) mice had a significant shift from $391 \pm 17$ to $525 \pm 28$ s/900 $(p<0.05)$, underlying that DF fails to affect the expression of morphine-induced CPP.

\section{Effects of WSE on ethanol- and morphine-induced ERK phosphorylation in AcbSh}

Figure 3A shows the effects of pre-treatment with vehicle (Veh) or WSE $(50 \mathrm{mg} / \mathrm{kg}) 30 \mathrm{~min}$ before the administration of vehicle (Veh) or ethanol (EtOH, $2 \mathrm{~g} / \mathrm{kg}$ ) (treatment) on the number of pERK-positive neurons (pERK expression) in the AcbSh. Two-way ANOVA with pre-treatment and treatment as categorical variables and pERK-positive cells counts as dependent variable revealed significant effects of pre-treatment $\left[F_{(1,24)}=7.86 ; p<0.05\right)$ and treatment $\left[F_{(1,24)}=5.03\right.$; $p<0.05)$ confirming that ethanol increases the number of pERK-positive neurons (Ibba et al. 2009; Porru et al. 2020) and suggesting that pre-treatment with WSE may significantly prevent ethanol-induced ERK phosphorylation $(p<0.05)$. Figure 3B shows the effects of pre-treatment with vehicle (Veh) or WSE $(50 \mathrm{mg} / \mathrm{kg}) 30 \mathrm{~min}$ before the administration of vehicle (Veh) or morphine (MOR, $5 \mathrm{mg} / \mathrm{kg}$ ) (treatment) on the number of pERK-positive neurons in the AcbSh. Two-way ANOVA with pre-treatment and treatment as categorical variables and pERK-positive cells counts as dependent variable revealed significant effects of pre-treatment $\left[F_{(1,30)}=15.04 ; p<0.005\right)$ and treatment $\left[F_{(1,30)}=7.16\right.$; $p<0.05]$ and a significant pre-treatment by treatment interaction $\left[F_{(1,30)}=10.40 ; p<0.005\right]$. Post-hoc analysis using the Newman-Keuls test confirmed that morphine increases the number of pERK-positive neurons in the AcbSh (Rosas et al. 2016) and showed that pre-treatment with WSE significantly prevents this effect $(p<0.05)$. Representative images of these effects are shown in Fig. 5.

\section{Effects of DF on ethanol- and morphine-induced ERK phosphorylation in AcbSh}

Figure 4A shows the effects of pre-treatment with Veh or DF $(2 \mathrm{mg} / \mathrm{kg}) 30 \mathrm{~min}$ before the administration of vehicle
Fig. 3 Effects of acute administration of WSE $(50 \mathrm{mg} / \mathrm{kg}$ i.p. $)$ on the expression of ethanol $(2 \mathrm{~g} / \mathrm{kg}$ i.p.)- (A) and morphine $(5 \mathrm{mg} / \mathrm{kg}$ i.p.)-(B) elicited pERK-positive neurons in the AcbSh of adult male CD1 mice. Data are shown as mean + SEM of pERK-positive neurons/area. \#indicates a significant difference $(p<0.05)$ vs preconditioning, same experimental group in Fig. 3A; ${ }^{\# \text { indicates a }}$ significant difference $(p<0.05)$ vs all groups in Fig. 3B
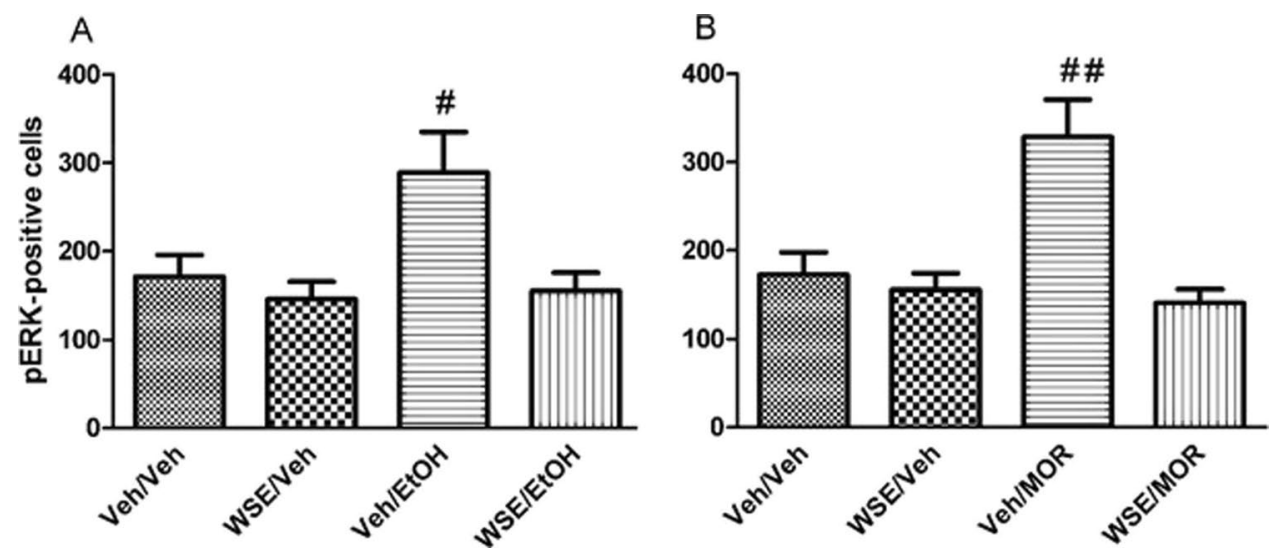
Fig. 4 Effects of acute administration of DF ( $2 \mathrm{mg} / \mathrm{kg}$ i.p.) on the expression of ethanol ( $2 \mathrm{~g} / \mathrm{kg}$ i.p.)- (A) and morphine (5 mg/kg i.p.)- (B) elicited pERK-positive neurons in the AcbSh of adult male CD1 mice. Data are shown as mean + SEM of pERK-positive neurons/area. \#indicates a significant difference $(p<0.05)$ vs all groups
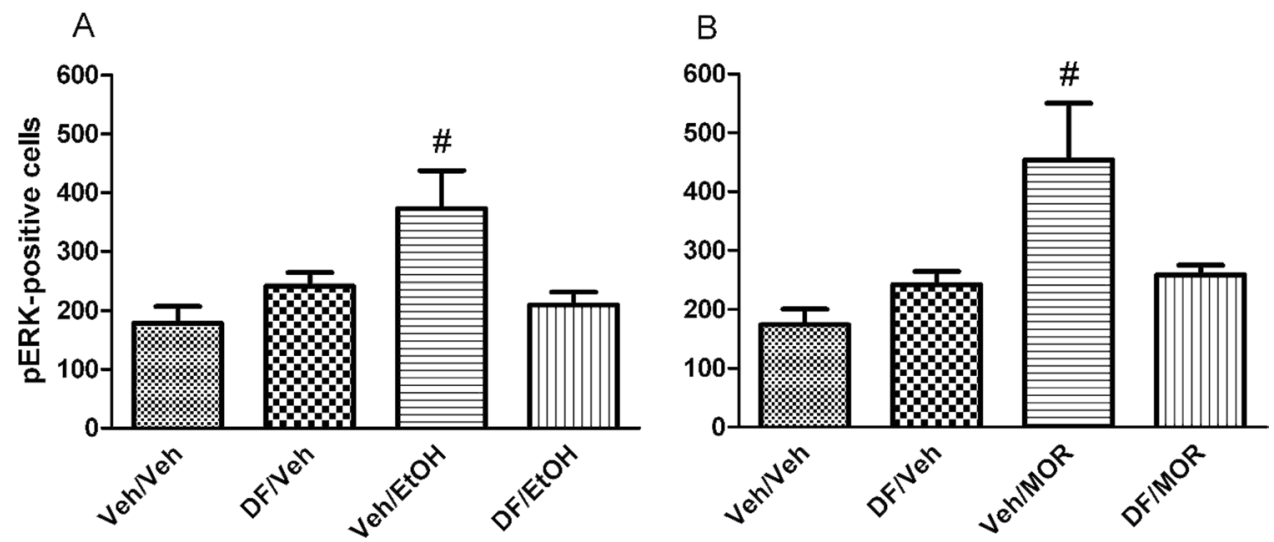

VEH/VEH

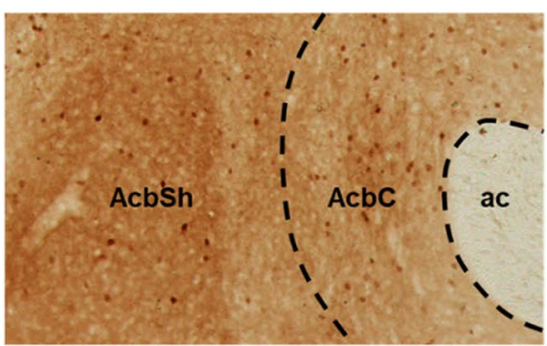

VEH/EtOH

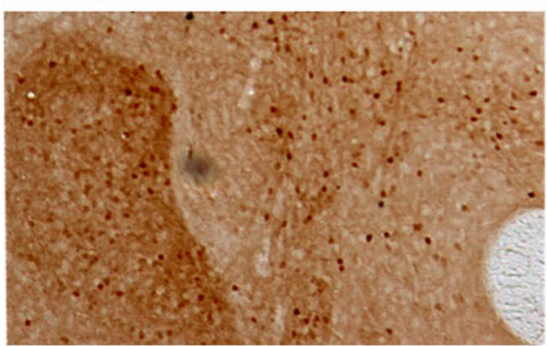

VEH/MOR

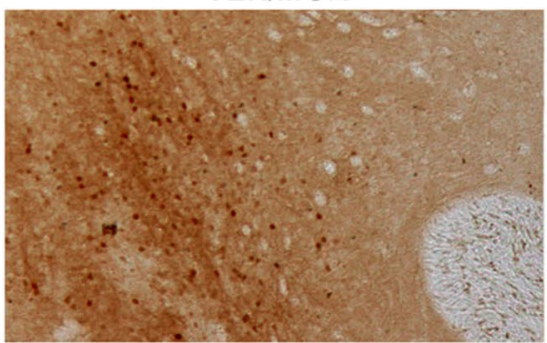

WSE/VEH

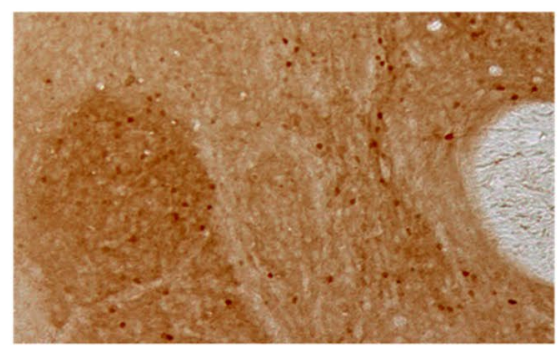

WSE/EtOH

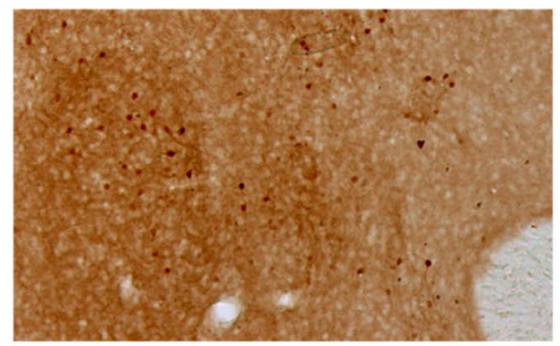

WSE/MOR

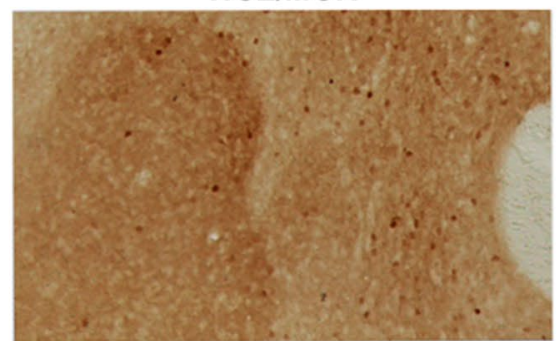

DF/VEH

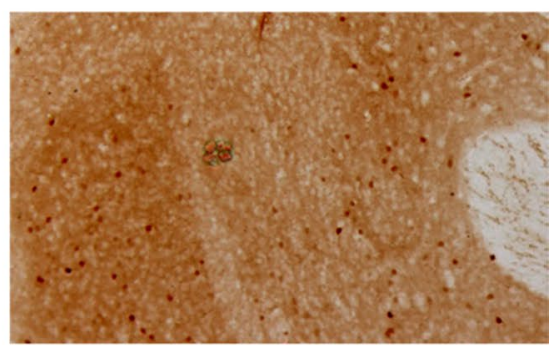

DF/EtOH

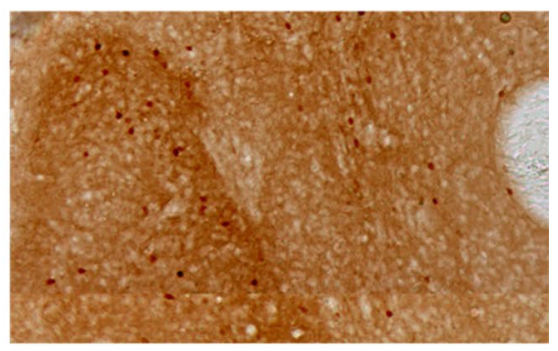

DF/MOR

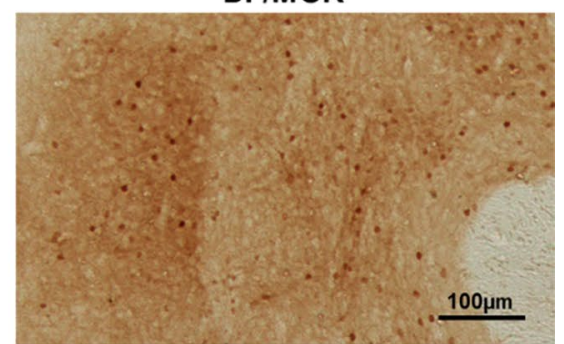

Fig. 5 Low (10X) magnification demonstrative images of the effects of the acute administration of WSE and DF on ethanol- and morphine-elicited pERK-immunostaining in the AcbSh from mice rep- resentative of pre-treatment/treatment groups shown in Figs. 3 and 4. Abbreviations: $A c b C$, nucleus accumbens core; $A c b S h$, nucleus accumbens shell; $a c$, anterior commissure
(Veh) or ethanol (EtOH, $2 \mathrm{~g} / \mathrm{kg}$ ) (treatment) on the number of pERK-positive neurons ( $\mathrm{pERK}$ expression) in the AcbSh. Two-way ANOVA with pre-treatment and treatment as categorical variables and pERK-positive cells counts as dependent variable revealed significant effects of treatment $\left[F_{(1,27)}=4,95 ; p<0.05\right]$ and a significant pretreatment by treatment $\left[F_{(1,27)}=9,58 ; p<0.005\right]$ interaction.
Post-hoc analysis using the Newman-Keuls test confirmed that EtOH increases the number of AcbSh pERK-positive neurons (Ibba et al. 2009; Porru et al. 2020) and showed that pre-treatment with DF prevents this effect $(p<0.05)$. Figure 4B shows the effects of pre-treatment with vehicle (Veh) or DF (2 mg/kg) $30 \mathrm{~min}$ before the administration of vehicle (Veh) or morphine (MOR, $5 \mathrm{mg} / \mathrm{kg}$ ) on the number 
of pERK-positive neurons in the AcbSh. Two-way ANOVA with pre-treatment and treatment as categorical variables and positive cells counts as dependent variable revealed significant effects of treatment $\left[F_{(1,28)}=7.97 ; p<0.05\right]$ and a significant pre-treatment by treatment $\left[F_{(1,28)}=6.62\right.$; $p<0.05]$ interaction. Post-hoc analysis using the NewmanKeuls test confirmed that morphine increases the number of AcbSh pERK-positive neurons (Rosas et al. 2016) and showed that pre-treatment with DF significantly prevents this effect $(p<0.05)$. Representative images of these effects are shown in Fig. 5.

\section{Discussion}

Previous studies have shown that WSE prevents both ethanol (Spina et al. 2015)- and morphine (Ruiu et al. 2013)-elicited acquisition of CPP as well as both ethanol- and morphineelicited CPP expression, i.e. the ability of environmental stimuli, conditioned to both ethanol (Spina et al. 2015) and morphine (Ruiu et al. 2013), to determine a positive sidepreference shift (CPP expression) at the post-conditioning test.

In fact, failure of classical pharmacological approaches (Lu et al. 2006) to treat drug addiction in humans has triggered the scientific interest on the application of phytomedicine and natural remedies for the treatment of drug addiction. In particular, the efficacy of WSE in pre-clinical models of drug addiction is strongly supported by over a decade of research (Gupta and Rana 2008; Kasture et al. 2009; Kulkarni and Ninan 1997; Peana et al. 2014; Ruiu et al. 2013; Spina et al. 2015; Bassareo et al. 2019). Thus, as a follow-up of previous studies from our laboratory, the present investigation was aimed at (i) characterizing further the potentially beneficial application of WSE to counteract the ability of acutely administered ethanol (Ibba et al. 2009; Porru et al. 2020, 2021; Rosas et al. 2017) and morphine (Rosas et al. 2016) to increase ERKs phosphorylation in the AcbSh and (ii) establishing whether WSE's active compound, docosanyl ferulate (Maccioni et al. 2021; Sonar et al. 2019), may be responsible for such effects as well as for WSE's effects on acquisition and expression of ethanol- and morphine-elicited CPP. The results of the present behavioural experiments confirm that ethanol (Spina et al. 2015) and morphine (Ruiu et al. 2013) elicit a significant CPP. The present results also reveal that DF, at the dose of $2 \mathrm{mg} /$ $\mathrm{kg}$, fully effective in exerting anxiolytic properties, without showing sedative, amnesic, motor impairing and motivational effects (Maccioni et al. 2021), significantly prevents the acquisition (Figs. 1A and 2A) but not the expression (Figs. 1B and 2B) of ethanol- and morphine-elicited CPP. Moreover, these data appear in partial agreement with our previous reports on the effects of WSE on acquisition and expression of ethanol- and morphine-elicited CPP, suggesting that the $\mathrm{GABA}_{\mathrm{A}} \mathrm{R}$-mimetic component, represented by $\mathrm{DF}$, is critical for WSE's ability to affect the acquisition but not the expression of CPP elicited by ethanol and morphine. This interpretation is supported by the observation that AcbSh DA has been reported to be critical for the acquisition, but not the expression, of morphine-elicited CPP (Fenu et al. 2006) and appears overall in agreement with the role played by mesolimbic DA in the associative learning ( $\mathrm{Di}$ Chiara 1998; Di Chiara and Bassareo 2007) at the basis of CPP acquisition (Di Chiara et al. 2004). Accordingly, via a $\mathrm{GABA}_{\mathrm{A}} \mathrm{R}$-mediated mechanism, WSE was reported to significantly suppress the stimulatory actions of both ethanol and morphine on the neuronal firing of ventral tegmental area DA neurons (Bassareo et al. 2019) and to prevent ethanol- and morphine-mediated increases of AcbSh DA release (Bassareo et al. 2019).

The complex relationship between $\mathrm{GABA}_{\mathrm{A}} \mathrm{R}$ modulators and the reinforcing properties of both ethanol and morphine has been addressed, although with no conclusive results, in the literature. In particular, studies investigating the interactions between $\mathrm{GABA}_{\mathrm{A}} \mathrm{R}$ modulators and the reinforcing properties of ethanol showed that $\mathrm{GABA}_{\mathrm{A}} \mathrm{R}$ ligands, both agonists (Hodge et al. 1995) and antagonists (Hodge et al. 1995; June et al. 1998) reduce ethanol self-administration and that $\mathrm{GABA}_{\mathrm{A}} \mathrm{R}$ antagonists increase ethanol-induced CPP and conditioned taste aversion in mice (Chester and Cunningham 1999). Moreover, in addition to such uncertainty on the role of $\mathrm{GABA}_{\mathrm{A}} \mathrm{R}$ on the reinforcing properties of ethanol and morphine, these results also suggest that rather than being related to the actions of ethanol and morphine, the involvement of $\mathrm{GABA}_{\mathrm{A}} \mathrm{R}$ may be related to their critical role in the learning process at the basis of the acquisition of the conditioned response. Furthermore, the present behavioural findings also indicate that other components of WSE, besides DF, may be responsible for WSE's ability to affect the expression of drug-induced CPP. This conclusion is fully compatible, in a complementary perspective, with the observation that distinct neural processes and anatomical structures may differentially underlie distinct phases of drugelicited place conditioning (Bardo 1998; Tzschentke 2007).

The results of the present study also confirm that both ethanol (Porru et al. 2020, 2021; Rosas et al. 2017) and morphine (Rosas et al. 2016; Valjent et al. 2004) activate ERKs phosphorylation in the AcbSh of CD1 mice and show for the first time that both WSE $(50 \mathrm{mg} / \mathrm{kg})$ and DF $(2 \mathrm{mg} /$ $\mathrm{kg}$ ) are able to prevent these increases. The acute effects of $W S E$ and DF in the prevention of either ethanol- or morphine-induced ERKs phosphorylation in the AcbSh was assessed, in distinct cohorts of animals, to better define the molecular mechanisms leading to WSE's and DF's prevention of the acquisition of ethanol- or morphine-elicited CPP. Thus, whilst we acknowledge that this evidence is indirect, 
since obtained from mice that had no conditioning, our suggestion that WSE and DF may contrast the acquisition of ethanol- or morphine-elicited CPP by averting ERKs phosphorylation in the AcbSh is also supported by the critical role of pERK in associative learning (Gerdjikov et al. 2004; Marotta et al. 2014; Salzmann et al. 2003). Moreover, these findings appear overall in agreement with the observation that activated ERKs play a critical role in the conditioned approach behaviour elicited by addictive drugs as assessed in the place conditioning paradigm (Gerdjikov et al. 2004; Lu et al. 2006; Rosas et al. 2018; Salzmann et al. 2003; Spina et al. 2010; Valjent et al. 2000, 2001) but also with the ability of WSE, via a GABA $\mathrm{A}_{\mathrm{A}} \mathrm{R}$-mediated mechanism, to control ethanol- and morphine-stimulated AcbSh DA transmission (Bassareo et al. 2019) as well as with the role of DA in ethanol (Ibba et al. 2009)- and morphine (Rosas et al. 2016)-elicited ERK phosphorylation in the AcbSh. However, whilst all this reasoning applies coherently to the recognition of the mesolimbic dopaminergic system in place conditioning (Di Chiara et al. 2004; Tzschentke 2007), we also acknowledge that other brain areas, such as the hippocampus (Bagherpasand et al. 2019; Zhang et al. 2016) as well as pERK expression therein (Bagherpasand et al. 2019; Zhang et al. 2016), may be critically responsible for the acquisition of place conditioning. The relationship between $\mathrm{GABA}_{\mathrm{A}} \mathrm{R}$ and ERKs phosphorylation can also be interpreted in light of the observation that a putative phosphorylation site for ERKs was found in almost all known alpha subunits of the $\mathrm{GABA}_{\mathrm{A}} \mathrm{R}$, including the ubiquitously expressed alpha1 subunit (Bell-Horner et al. 2006). Interestingly, this study demonstrated that this site is functional and that pERK acts as a negative $\mathrm{GABA}_{\mathrm{A}} \mathrm{R}$ modulator as its inhibition, through pharmacological inhibition of MEK, results in an amplification of $\mathrm{GABA}_{\mathrm{A}} \mathrm{R}$ currents in HEK293 cells (Bell-Horner et al. 2006). Hence, the relationship between pERK and $\mathrm{GABA}_{\mathrm{A}} \mathrm{R}$ might be bidirectional, as $\mathrm{GABA}_{\mathrm{A}} \mathrm{R}$ agonists lead to a decrease in pERK expression and reduction of pERK expression by MEK inhibition, in turn, induces an increase of $\mathrm{GABA}_{\mathrm{A}} \mathrm{R}$-mediated currents.

Overall, the previous (Ruiu et al. 2013; Spina et al. 2015) and present data on WSE support the view that selective products of phytomedicine and natural remedies may be useful strategies for the treatment of brain disorders as well as for further understanding the underpinning subcellular mechanisms. The relevance of these findings comes not only from this observation but also because DF's data contribute significantly to characterize the relationship between WSE, pERK, two distinct phases of the place conditioning paradigm and $\mathrm{GABA}_{\mathrm{A}} \mathrm{R}$ pointing to $\mathrm{DF}$ as a potential pharmacological agent for the management of drug addiction. In fact, DF already resulted as a promising molecule in its first behavioural characterization, which showed an anxiolytic activity comparable to the $\mathrm{GABA}_{\mathrm{A}} \mathrm{R}$ positive modulator, diazepam (Maccioni et al. 2021; Nutt and Blier 2016), however combined with the lack of undesired motor and mnemonic effects, of addictive potential as well as of the diazepam's property to potentiate ethanol's depressant central effects (Maccioni et al. 2021).

In conclusion, these results may support the suggestion of the suitability of both WSE and DF as strategies for the management of distinct phases of drug addiction, the establishment of associative memories (modelled by the CPP acquisition) and the triggering of drug-seeking by contextual conditioned stimuli (modelled by the CPP expression). This suggestion is further supported on one hand by the observation that both Withania somnifera (Dar et al. 2015) and DF (Maccioni et al. 2021) present a robust anxiolytic profile and, on the other hand, by the observation that anxiety disorders and drug addiction may co-occur at high rates (Smith and Book 2008). Hence, the anxiolytic profile and the ability to prevent ethanol- and morphine-elicited CPP may truly be useful in the development of an efficient therapeutical strategy, especially considering the lack of undesired effects. Additional behavioural and biochemical studies will have to be performed to characterize further their suitability for the treatment of drug addiction.

\section{Declarations}

Conflict of interest The authors declare no competing interests.

Open Access This article is licensed under a Creative Commons Attribution 4.0 International License, which permits use, sharing, adaptation, distribution and reproduction in any medium or format, as long as you give appropriate credit to the original author(s) and the source, provide a link to the Creative Commons licence, and indicate if changes were made. The images or other third party material in this article are included in the article's Creative Commons licence, unless indicated otherwise in a credit line to the material. If material is not included in the article's Creative Commons licence and your intended use is not permitted by statutory regulation or exceeds the permitted use, you will need to obtain permission directly from the copyright holder. To view a copy of this licence, visit http://creativecommons.org/licenses/by/4.0/.

\section{References}

Abrahao KP, Salinas AG, Lovinger DM (2017) Alcohol and the brain: neuronal molecular targets, synapses, and circuits. Neuron 96(6):1223-1238. https://doi.org/10.1016/j.neuron.2017.10.032

Acquas E, Di Chiara G (1994) D1 receptor blockade stereospecifically impairs the acquisition of drug-conditioned place preference and place aversion. Behav Pharmacol 5(6):555-569. https://doi.org/ 10.1097/00008877-199410000-00001

Acquas E, Pisanu A, Spiga S et al (2007) Differential effects of intravenous $\mathrm{R}, \mathrm{S}-( \pm)-3,4$ methylenedioxymethamphetamine (MDMA, Ecstasy) and its $\mathrm{S}(+)$ - and $\mathrm{R}(-)$-enantiomers on dopamine transmission and extracellular signal regulated kinase phosphorylation 
(pERK) in the rat nucleus accumbens shell and core. J Neurochem 102:121-132. https://doi.org/10.1111/j.1471-4159.2007.04451.x

Axley PD, Richardson CT, Singal AK (2019) Epidemiology of alcohol consumption and societal burden of alcoholism and alcoholic liver disease. Clin Liver Dis 23(1):39-50. https://doi.org/10.1016/j.cld. 2018.09.011

Bagherpasand N, Mehri S, JafariShahroudi M, Tabatabai SM, Khezri A, Fathi M, Abnous K, Imenshahidi M, Hosseinzadeh H (2019) Effect of topiramate on morphine-induced conditioned place preference (CPP) in rats: role of ERK and CREB proteins in hippocampus and cerebral cortex. Iran J Pharm Res. 18(4):20002010. https://doi.org/10.22037/ijpr.2019.1100873

Bardo MT (1998) Neuropharmacological mechanisms of drug reward: beyond dopamine in the nucleus accumbens. Crit Rev Neurobiol 12(1-2):37-67. https://doi.org/10.1615/critrevneu robiol.v12.i1-2.30

Bassareo V, Talani G, Frau R et al (2019) Inhibition of morphineand ethanol-mediated stimulation of mesolimbic dopamine neurons by Withania somnifera. Front Neurosci 13:545. https://doi. org/10.3389/fnins.2019.00545

Bassareo V, Frau R, Maccioni R et al (2021) Ethanol-dependent synthesis of salsolinol in the posterior ventral tegmental area as key mechanism of ethanol's action on mesolimbic dopamine. Front Neurosci 15:675061. https://doi.org/10.3389/fnins.2021.675061

Bell-Horner CL, Dohi A, Nguyen Q et al (2006) ERK/MAPK pathway regulates GABAA receptors. J Neurobiol 66(13):14671474. https://doi.org/10.1002/neu.20327

Benyamin R, Trescot AM, Datta S et al (2008) Opioid complications and side effects. Pain Physician 11(2 Suppl):S105-S120

Berhow MT, Hiroi N, Nestler EJ (1996) Regulation of ERK (extracellular signal regulated kinase), part of the neurotrophin signal transduction cascade, in the rat mesolimbic dopamine system by chronic exposure to morphine or cocaine. J Neurosci 16(15):4707-4715. https://doi.org/10.1523/jneurosci.16-1504707.1996

Berke JD, Hyman SE (2000) Addiction, dopamine, and the molecular mechanisms of memory. Neuron 25(3):515-532. https://doi.org/ 10.1016/s0896-6273(00)81056-9

Brami-Cherrier K, Valjent E, Hervé D et al (2006) Parsing molecular and behavioral effects of cocaine in mitogen- and stress-activated protein kinase-1-deficient mice. Neuroscience 25(49):1144411454. https://doi.org/10.1523/jneurosci.1711-05.2005

Chester JA, Cunningham CL (1999) GABA(A) receptors modulate ethanol-induced conditioned place preference and taste aversion in mice. Psychopharmacology 144(4):363-372. https://doi.org/ $10.1007 / \mathrm{s} 002130051019$

Correa M, Salamone JD, Segovia KN et al (2012) Piecing together the puzzle of acetaldehyde as a neuroactive agent. Neurosci Biobehav Rev. 36(1):404-430. https://doi.org/10.1016/j.neubiorev.2011.07. 009

Dar NJ, Hamid A, Ahmad M (2015) Pharmacological overview of Withania somnifera, the Indian Ginseng. Cell Mol Life Sci 72:4445-4460. https://doi.org/10.1007/s00018-015-2012-1

Di Chiara G (1998) A motivational learning hypothesis of the role of mesolimbic dopamine in compulsive drug use. J Psychopharmacol 12:54-67. https://doi.org/10.1177/026988119801200108

Di Chiara G (1999) Drug addiction as dopamine-dependent associative learning disorder. Eur J Pharmacol 375(1-3):13-30. https://doi. org/10.1016/s0014-2999(99)00372-6

Di Chiara G, Bassareo V (2007) Reward system and addiction: what dopamine does and doesn't do. Curr Opin Pharmacol 7(1):69-76. https://doi.org/10.1016/j.coph.2006.11.003

Di Chiara G, Bassareo V, Fenu S et al (2004) Dopamine and drug addiction: the nucleus accumbens shell connection. Neuropharmacology 47(Suppl 1):227-241. https://doi.org/10.1016/j.neuro pharm.2004.06.032
Fenu S, Spina L, Rivas E et al (2006) Morphine-conditioned singletrial place preference: role of nucleus accumbens shell dopamine receptors in acquisition, but not expression. Psychopharmacology 187(2):143-153. https://doi.org/10.1007/s00213-006-0415-2

Gerdjikov TV, Ross GM, Beninger RJ (2004) Place preference induced by nucleus accumbens amphetamine is impaired by antagonists of ERK or p38 MAP kinases in rats. Behav Neurosci 118:740-750. https://doi.org/10.1037/0735-7044.118.4.740

Gupta GL, Rana AC (2008) Effect of Withania somnifera Dunal in ethanol-induced anxiolysis and withdrawal anxiety in rats. Indian J Exp Biol 46(6):470-475

Hodge CW, Chappelle AM, Samson HH (1995) GABAergic transmission in the nucleus accumbens is involved in the termination of ethanol self-administration in rats. Alcohol Clin Exp Res 19(6):1486-1493. https://doi.org/10.1111/j.1530-0277.1995.tb010 12.x

Ibba F, Vinci S, Spiga S et al (2009) Ethanol-induced extracellular signal regulated kinase: role of dopamine D1 receptors. Alcohol Clin Exp Res 33:858-867. https://doi.org/10.1111/j.1530-0277. 2009.00907.x

June HL, Devaraju SL, Eggers MW et al (1998) Benzodiazepine receptor antagonists modulate the actions of ethanol in alcohol-preferring and -nonpreferring rats. Eur J Pharmacol 342(23):139-151. https://doi.org/10.1016/s0014-2999(97)01489-1

Kasture S, Vinci S, Ibba F et al (2009) Withania somnifera prevents morphine withdrawal-induced decrease in spine density in nucleus accumbens shell of rats: a confocal laser scanning microscopy study. Neurotox Res 16(4):343-355. https://doi.org/ 10.1007/s12640-009-9069-2

Koob GF (2006) The neurobiology of addiction: a neuroadaptational view relevant for diagnosis. Addiction 101(Suppl 1):23-30. https://doi.org/10.1111/j.1360-0443.2006.01586.x

Koob GF, Le Moal M (2001) Drug addiction, dysregulation of reward, and allostasis. Neuropsychopharmacology 2:97-129. https://doi.org/10.1016/s0893-133x(00)00195-0

Kulkarni SK, Ninan I (1997) Inhibition of morphine tolerance and dependence by Withania somnifera in mice. J Ethnopharmacol 57(3):213-217. https://doi.org/10.1016/s0378-8741(97)00064-0

Lin X, Wang Q, Ji J et al (2010) Role of MEK-ERK pathway in morphine-induced conditioned place preference in ventral tegmental area of rats. J Neurosci Res. 88(7):1595-604. https://doi. org/10.1002/jnr.22326

Lu L, Koya E, Zhai H et al (2006) Role of ERK in cocaine addiction. Trends Neurosci 29:695-703. https://doi.org/10.1016/j. tins.2006.10.005

Maccioni R, Setzu MD, Talani G et al (2018) Standardized phytotherapic extracts rescue anomalous locomotion and electrophysiological responses of TDP-43 Drosophila melanogaster model of ALS. Sci Rep 8(1):16002. https://doi.org/10.1038/ s41598-018-34452-1

Maccioni R, Cottiglia F, Maccioni E et al (2021) The biologically active compound of Withania somnifera (L.) Dunal, docosanyl ferulate, is endowed with potent anxiolytic properties but devoid of typical benzodiazepine-like side effects. J Psychopharmacol. 3:2698811211008588. https://doi.org/10.1177/0269881121 1008588

Marotta R, Fenu S, Scheggi S, Vinci S, Rosas M, Falqui A, Gambarana C, De Montis MG, Acquas E (2014) Acquisition and expression of conditioned taste aversion differentially affects extracellular signal regulated kinase and glutamate receptor phosphorylation in rat prefrontal cortex and nucleus accumbens. Frontiers in Behavioral Neuroscience 8. https://doi.org/ 10.3389/fnbeh.2014.00153

Mazzucchelli C, Vantaggiato C, Ciamei A et al (2002) Knockout of ERK1 MAP kinase enhances synaptic plasticity in the striatum 
and facilitates striatal-mediated learning and memory. Neuron 34(5):807-820. https://doi.org/10.1016/s0896-6273(02)00716-x

Muller DL, Unterwald EM (2004) In vivo regulation of extracellular signal-regulated protein kinase (ERK) and protein kinase $\mathrm{B}$ (Akt) phosphorylation by acute and chronic morphine. J Pharmacol Exp Ther 310(2):774-782. https://doi.org/10.1124/jpet. 104.066548

Nestler EJ (2001) Molecular neurobiology of addiction. Am J Addict 10:201-217. https://doi.org/10.1080/105504901750532094

Nutt DJ, Blier P (2016) Neuroscience-based Nomenclature (NbN) for Journal of Psychopharmacology. J Psychopharmacol 30:413-415. https://doi.org/10.1177/0269881116642903

Paxinos G, Franklin KBJ (2001) The mouse brain in stereotaxic coordinates, 2nd edn. Academic, Sydney

Peana AT, Muggironi G, Spina L et al (2014) Effects of Withania somnifera on oral ethanol self-administration in rats. Behav Pharmacol 25(7):618-628. https://doi.org/10.1097/fbp.0000000000000078

Porru S, Maccioni R, Bassareo V et al (2020) Effects of caffeine on ethanol-elicited place preference, place aversion and ERK phosphorylation in CD-1 mice. J Psychopharmacol 12:1357-1370. https://doi.org/10.1177/0269881120965892

Porru S, López-Cruz L, Carratalá-Ros C et al (2021) Impact of caffeine on ethanol-induced stimulation and sensitization: changes in ERK and DARPP-32 phosphorylation in nucleus accumbens. Alcohol Clin Exp Res 45(3):608-619. https://doi.org/10.1111/acer.14553

Rehm J, Gmel GE, Gmel G et al (2017) The relationship between different dimensions of alcohol use and the burden of disease-an update. Addiction 112:968. https://doi.org/10.1111/add.13757

Rosas M, Porru S, Fenu S et al (2016) Role of nucleus accumbens $\mu$ opioid receptors in the effects of morphine on ERK1/2 phosphorylation. Psychopharmacology 233(15-16):2943-2954. https:// doi.org/10.1007/s00213-016-4340-8

Rosas M, Porru S, Longoni R et al (2017) Differential effects of the MEK inhibitor SL327 on the acquisition and expression of ethanol-elicited conditioned place preference and aversion in mice. $\mathrm{J}$ Psychopharmacol 31(1):105-114. https://doi.org/10.1177/02698 81116675514

Rosas M, Porru S, Sabariego M et al (2018) Effects of morphine on place conditioning and ERK1/2 phosphorylation in the nucleus accumbens of psychogenetically selected Roman low- and highavoidance rats. Psychopharmacology 235:59-69. https://doi.org/ 10.1007/s00213-017-4740-4

Ruiu S, Longoni R, Spina L et al (2013) Withania somnifera prevents acquisition and expression of morphine-elicited conditioned place preference. Behav Pharmacol 24(2):133-143. https://doi.org/10. 1097/fbp.0b013e32835f3d15

Salzmann J, Marie-Claire C, Le Guen S et al (2003) Importance of ERK activation in behavioral and biochemical effects induced by MDMA in mice. Br J Pharmacol 140:831-838. https://doi.org/10. 1016/j.ejphar.2005.09.012

Singh N, Bhalla M, de Jager P et al (2011) An overview on ashwagandha: a Rasayana (rejuvenator) of Ayurveda. Afr J Tradit Complement Altern Med 8(5 Suppl):208-213. https://doi.org/10.4314/ ajtcam.v8i5s.9
Smith JP, Book SW (2008) Anxiety and substance use disorders: a review. Psychiatr times 25(10):19-23

Sonar VP, Fois B, Distinto S et al (2019) Ferulic acid esters and withanolides: in search of Withania somnifera GABAA receptor modulators. J Nat Prod 82:1250-1257. https://doi.org/10.1021/acs.jnatp rod.8b01023

Spina L, Longoni R, Vinci S et al (2010) Role of dopamine D1 receptors and extracellular signal regulated kinase in the motivational properties of acetaldehyde as assessed by place preference conditioning. Alcohol Clin Exp Res 34:607-616. https://doi.org/10. 1111/j.1530-0277.2009.01129.x

Spina L, Longoni R, Rosas M et al (2015) Withania somnifera Dunal (Indian ginseng) impairs acquisition and expression of ethanolelicited conditioned place preference and conditioned place aversion. J Psychopharmacol 29:1191-1199. https://doi.org/10.1177/ 0269881115600132

Sweatt JD (2004) Mitogen-activated protein kinases in synaptic plasticity and memory. Curr Opin Neurobiol 14:311-317. https://doi.org/ 10.1016/j.conb.2004.04.001

Tzschentke TM (2007) Measuring reward with the conditioned place preference (CPP) paradigm: Update of the last decade. Addict Biol 12:227-462. https://doi.org/10.1111/j.1369-1600.2007.00070.x

Valjent E, Corvol J, Page C et al (2000) Involvement of the extracellular signal-regulated kinase cascade for cocaine-rewarding properties. J Neurosci 20:8701-8709. https://doi.org/10.1523/jneurosci.2023-08701.2000

Valjent E, Caboche J, Vanhoutte P (2001) Mitogen-activated protein kinase/extracellular signal-regulated kinase induced gene regulation in brain. Mol Neurobiol 23:83-99. https://doi.org/10.1385/ $\mathrm{mn}: 23: 2-3: 083$

Valjent E, Pagès C, Hervé D et al (2004) Addictive and non-addictive drugs induce distinct and specific patterns of ERK activation in mouse brain. Eur J Neurosci 19(7):1826-1836. https://doi.org/10. 1111/j.1460-9568.2004.03278.x

Valjent E, Pascoli V, Corvol J et al (2005) Regulation of a protein phosphatase cascade allows convergent dopamine and glutamate signals to activate ERK in the striatum. PNAS 102:491-496. https:// doi.org/10.1073/pnas.0408305102

Volkow ND, Morales M (2015) The brain on drugs: from reward to addiction. Cell 162(4):712-25. https://doi.org/10.1016/j.cell.2015. 07.046

Zhang J, Wang N, Chen B, Wang Y, He J, Cai X, Zhang H, Wei S, Li S (2016) Blockade of Cannabinoid CB1 receptor attenuates the acquisition of morphine-induced conditioned place preference along with a downregulation of ERK, CREB phosphorylation, and BDNF expression in the nucleus accumbens and hippocampus. Neurosci Lett 630:70-76. https://doi.org/10.1016/j.neulet. 2016.07.047

Publisher's note Springer Nature remains neutral with regard to jurisdictional claims in published maps and institutional affiliations. 